\title{
Numerical study of the effect of blood vessel on the microwave ablation shape
}

\author{
Xiaohui Nie, Qun Nan*, Xuemei Guo and Zhen Tian \\ College of Life Science and Bioengineering, Beijing University of Technology, Beijing, 100124, China
}

\begin{abstract}
The existence of large blood vessels seriously impacts the results of microwave ablation on heat transfer of surrounding tissue, and the research of influences about large blood vessels could be essential and significant. The temperature distribution in the tissue was analyzed with a microwave heating source by finite element method. The model, where the blood vessel is parallel to antenna, has different distances from antenna to blood vessel. As distance was greater than $20 \mathrm{~mm}$, the effect of blood vessel that was parallel to antenna was ignored and the ablation area was elliptical-like. When distance was less than $10 \mathrm{~mm}$, the part of asymmetrical coagulated area was on the right side of blood vessel. Therefore, the temperature contour by different conditions could provide numerical references, which is whether to block blood vessel or not, to achieve the aim of guiding the clinical practice, according to the locations of tumor and blood vessel.
\end{abstract}

Keywords: Microwave ablation, blood vessel, microwave antenna, ablation area

\section{Introduction}

The microwave ablation therapy of which is one of the most effectual methods as the treatment of liver tumors, is especially rapid developed and extensive applied. Seki [1] published his clinical study about the microwave coagulation therapy where he used ultrasound monitoring to treat small liver tumors firstly in 1994.

Most researchers think that the malignant tissues could be quickly and completely destroyed by applying temperature of $54^{\circ} \mathrm{C}$ for $1 \mathrm{~min}$ than the normal hepatocytes, because of the malignant tissues more sensitive to heat [2]. So increasing the temperature of malignant tissues to above $54{ }^{\circ} \mathrm{C}$ by microwave energy is the aim through ablation therapy in order to destroy the tumor.

In allusion to a large number of vitro and vivo experiments, some people have found that ignoring the effects of blood vessel could generate the errors of result in microwave ablation and bring about inaccuracy surgical planning. Thereupon, Y.Y. Sun [3] considered that due to existence of the blood vessels, bio-heat transfer could be lost to lead to bad ablation areas. For the sake of achieving to acquire accurate data and guide treatment planning, the numerical simulation has been an indispensable process, Nan Qun [4] has put forwards to the effect of large blood vessel by a water-

\footnotetext{
* Address for correspondence: Qun Nan, College of Life Science and Bioengineering, Beijing University of Technology, Beijing, 100124, China. Tel.: +6739 2855; Fax:+6739 2855; E-mail: nanqun@bjut.edu.cn.
}

0959-2989/15/\$35.00 @ 2015 - IOS Press and the authors. 
cooled microwave antenna in the thermal ablation.

According to the various reasons including the various kinds of blood flow status and the influence between the blood flow and ablation area [5], studying large blood vessels causing a tremendous impact on the heat transfer of tissue has been the major difficulty during the past few years. Due to the fact that the large blood vessel near the tumor is a common growth morphology of liver cancer, some works aim to demonstrate the effects of large blood vessels on temperature distribution in some studies [6], where they focus on the blood vessel near the tumor. In general, numerical simulation plays an important role to assist and improve the therapy in the study of clinic. Based on our previous works [4] that only researched one mathematical model at a location where the antenna is perpendicular to the blood vessel, the other mathematical model which is that the antenna is parallel to the blood vessel should be considered and analyzed by finite element method of Pennes bioheat transfer equation. In the clinic, as the theoretical reference, numerical results are scientific and necessary to help physicians to decide whether to occlude the blood vessel or not.

\section{Methods}

According to the microwave generator with output power of $0-100 \mathrm{~W}$ and the special antenna within cooling water to prevent destroying, the antenna numerical model is constructed in Figure 1. The 3-D numerical model to be simulated, of which blood vessel is located parallel to microwave antenna, is showed in Figure 2. Among that, the blood vessel diameter and length are $3 \mathrm{~mm}$ and $10 \mathrm{~cm}$ respectively. Besides, D is the distance from the blood vessel to the microwave antenna in the model.

The heat transfer is a priority research in the simulation of microwave ablation, in addition, the process of ablation could be regarded as energy transformation through microwave mechanism which launches energy to convert into heat. So the heat transfer should be expressed completely by the Pennes bioheat equation [7].

$$
\rho c \frac{\partial T}{\partial \tau}=k \nabla^{2} T+\omega_{b} c_{b}\left(T_{b}-T\right)+Q_{m}+Q_{r}
$$

Where: $\rho$ is tissue density $\left(\mathrm{kg} / \mathrm{m}^{3}\right) ; c$ and $c_{b}$ are specific heats of tissue and blood respectively $\left(\mathrm{J} / \mathrm{kg} \cdot{ }^{\circ} \mathrm{C}\right) ; k$ is the thermal conductivity of tissue $\left(\mathrm{J} / \mathrm{m} \cdot \mathrm{s} \cdot{ }^{\circ} \mathrm{C}\right) ; \omega_{b}$ is blood perfusion $\left(\mathrm{kg} / \mathrm{s} \cdot \mathrm{m}^{3}\right) ; T$ and $T_{b}$ are temperatures of tissue and blood $\left({ }^{\circ} \mathrm{C}\right) ; Q_{m}$ is the energy generated by metabolism $\left(\mathrm{J} / \mathrm{m}^{3} \cdot \mathrm{s}\right)$; and

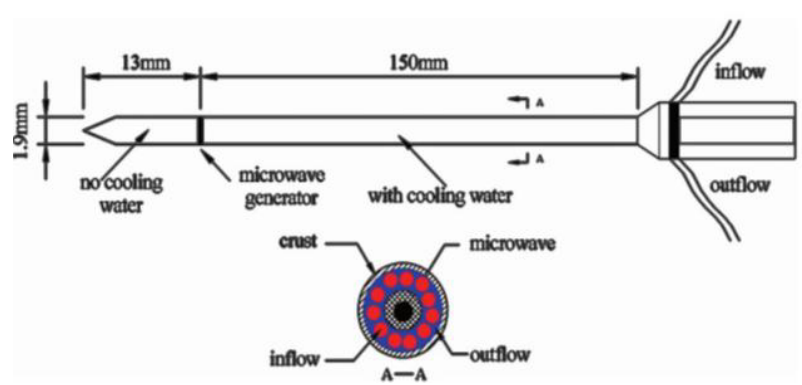

Fig. 1. Microwave antenna geometry.

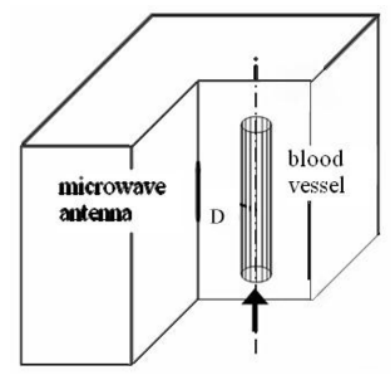

Fig. 2. Blood vessel parallel to microwave antenna 3D numerical model. 
$Q_{r}$ is the energy generated by microwave $\left(\mathrm{J} / \mathrm{m}^{3} \cdot \mathrm{s}\right)$.

In consideration of the static phantom, metabolism or blood perfusion is inexistence in the simulation, so $Q_{m}$ and $\omega_{\mathrm{b}}$ could be considered to be zero in Eq. (1). Moreover, less effect on the heat loss of perfusion by the large blood vessel causes to ignore the value of heat loss of perfusion. And at the first time of heating up (0-10s), the conductive heat transfer impact on temperature is very small [8], which can be negligibility $\left(k \nabla^{2} T=0\right)$. Thus, Eq. (1) could be simplified at the beginning of heating up, shown in Eq. (2):

$$
Q_{r}=\rho c \frac{\partial T}{\partial \tau}=\rho \times S A R
$$

Therefore $Q_{r}$ is proportional to the temperature of the time derivative from Eq. (2). Among that, SAR (Specific Absorption Rate) represents the heating ability of tissues during the thermal ablation $(\mathrm{W} / \mathrm{kg}$ ). Based on the research of X.Y. Yang [9], an analytical expression of Eq. (3) [9] could be presented by fitting the $Q_{r}$ data, which reason is that the temperature distribution depends on the microwave energy in the initial ten seconds. Table 1 gives the fitted coefficients.

$$
Q_{r} / \rho c=a \times \exp (-\exp (-(r-b) / c)-(r-b) / c+1) \times \exp (-\exp (-(z-d) / e)-(z-d) / e+1)
$$

Considering the large blood vessel influence on the thermal field, we neglected metabolism and blood perfusion. The properties [10] of ex-vivo liver are shown in Table 2. Besides, the model is set as $37^{\circ} \mathrm{C}$ at initial condition on the principle of Dirichlet boundary condition. The microwave power is set as $60 \mathrm{~W}$ and the heating time is 5 minutes. And the velocity of the cooling water is $0.22 \mathrm{~m} / \mathrm{s}$ [10].

The mesh sensitivity analysis has been done for the first model in our research. On the basis of acceptable error less than $1 \%$ in principle and the percentage D-value compared the third mesh densities with the fourth one, which is calculated as $0.5 \%$ in the quantities of peak temperatures, the element numbers are determined about one hundred and fifty thousand for all our models.

Table 1

The coefficients of Eq. (3)

\begin{tabular}{lllll}
\hline $\mathrm{a}$ & $\mathrm{b}$ & $\mathrm{c}$ & $\mathrm{d}$ & $\mathrm{e}$ \\
\hline 14.23 & 0.05 & 0.19 & -0.28 & 0.53 \\
\hline
\end{tabular}

Table 2

The properties of ex-vivo liver

\begin{tabular}{llll}
\hline Temperature $\left({ }^{\circ} \mathrm{C}\right)$ & $20-70$ & $80-100$ & $110-120$ \\
\hline $\mathrm{k}\left(\mathrm{J} /\left(\mathrm{m} \cdot \mathrm{s} \cdot{ }^{\circ} \mathrm{C}\right)\right.$ & 0.459 & 0.868 & 1.462 \\
\hline$\rho_{(\mathrm{kg} / \mathrm{m} 3)}$ & 1020 & 1020 & 1020 \\
\hline$C_{\left(\mathrm{J} / \mathrm{kg} \cdot{ }^{\circ} \mathrm{C}\right)}$ & 3627 & 3859 & 3988 \\
\hline
\end{tabular}




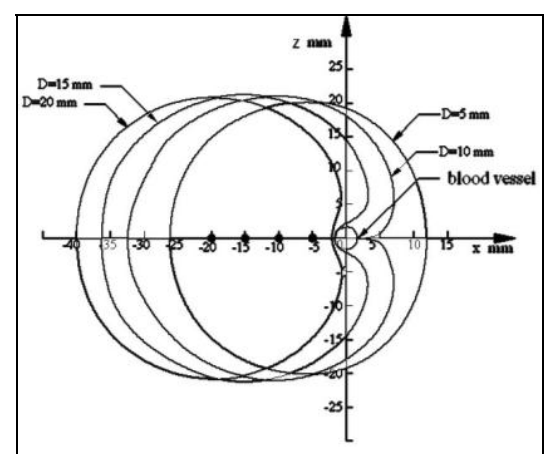

Fig. 3. The isotherms $\left(54^{\circ} \mathrm{C}\right)$ at different distances when blood vessel is parallel to antenna.

\section{Results}

The ablation area, which was negatively affected, was always elliptical-like when the distance was in excess of $20 \mathrm{~mm}$. While the distance was less than $10 \mathrm{~mm}$, the ablation shape was not symmetrical around the antenna with large temperature gradients near the blood vessel.

The horizontal isotherms $\left(54^{\circ} \mathrm{C}\right)$, as seen in Figure 3, are shown with different distances from antenna to the large blood vessel when blood vessel was parallel to antenna. In addition, the center of blood vessel was the ordinate origin in a planing surface. As the distance was $5 \mathrm{~mm}$, the region of

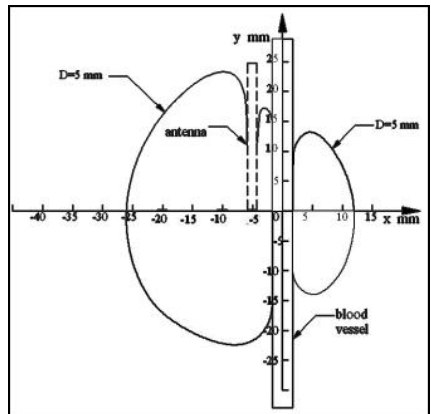

(a)

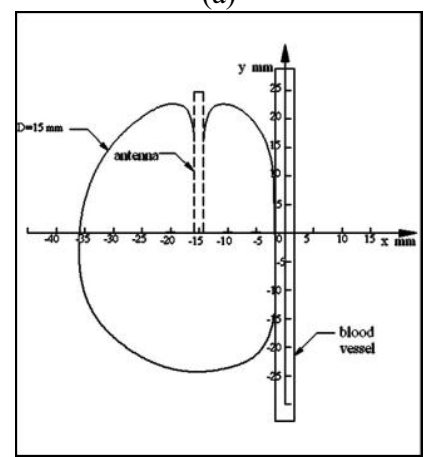

(c)

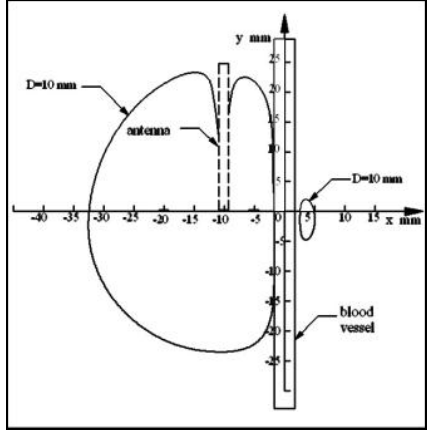

(b)

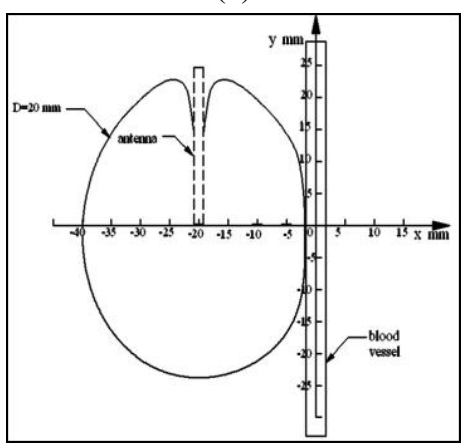

(d)

Fig. 4. The isotherms $\left(54^{\circ} \mathrm{C}\right)$ at various distances from antenna to the blood vessel (a) $\mathrm{D}=5 \mathrm{~mm}$ (b) $\mathrm{D}$ $=10 \mathrm{~mm}$ (c) $\mathrm{D}=15 \mathrm{~mm}$ (d) $\mathrm{D}=20 \mathrm{~mm}$. 
coagulation was approximately ellipsoidal and the vessel had been ablated. The coagulative area was approximating heart shape as the distance was set as $10 \mathrm{~mm}$. The blood vessel couldn't be ablated when the value of distance was greater than $15 \mathrm{~mm}$. But the ablation area was sunken until the distance exceeded $20 \mathrm{~mm}$. From this picture, the regular pattern, which was that the farther the distance was, the more sunken the ablation area was. It's showed the $54^{\circ} \mathrm{C}$ vertical isotherms with different distances between antenna and the blood vessel which was parallel to the antenna in Figure 4. As the distance was less than $10 \mathrm{~mm}$, it was still caused as ablation area at the right side of the blood vessel (Figures 4(a) and 4(b)). When the distance was greater than $10 \mathrm{~mm}$, it was showed that there was no coagulation region on the right side of the coordinate (Figures 4(c) and 4(d)). This situation is the same to that of the perpendicular relationship [4] between the large vessel and the microwave antenna, meanwhile, the ablation area shape on the left side of the antenna was almost the same.

\section{Discussion}

According to the results by finite element method, the influence on the temperature contour $\left(54^{\circ} \mathrm{C}\right)$ by large blood vessel would cause the ablation asymmetrical shape in the model which is that the antenna is parallel to blood vessel.

Based on the different temperature contours, the distance from antenna to large blood vessel is really crucial to achieve the perfect ablation area and shape. Compared with our previous research works [4] which are relative to the simulation of different distances, our result is similar to that of other model of blood vessel perpendicular to microwave antenna. As the distance is less than $10 \mathrm{~mm}$, causing the coagulated region on the right side of coordinate leads to asymmetrical ablation. However, the ablation area that is affected more and more weakly by large blood vessel is usually presented as elliptical-like when the distance exceeded $20 \mathrm{~mm}$. So, it's believed that when the distance is greater than $20 \mathrm{~mm}$, the effect of blood vessel could be ignored and the ablation area is completely ellipticallike. In connection with the distance less than $10 \mathrm{~mm}$, considering and taking some scientific measures to the large blood vessel is necessary and integral in the clinic, such as blockading blood vessel to prevent wrecking the ablation.

In conclusion, it's obvious that the location between blood and microwave antenna has effect on the ablation area and shape in the model of which the blood vessel is parallel to antenna, which is the same as the arterial bifurcation blood vessel [11].

Limitations also exist in our study. The angle between antenna and blood vessel only involved 0 degree and 90 degree. In fact any angle is possible in clinic. What's more, we should improve the design of simulations to include more realistic settings, such as more different vessel diameters

\section{Conclusions}

Based on the results of some related data analysis, the influence of different distances from antenna to blood vessel is obvious in the simulation of microwave ablation. Furthermore, as the distance is less than $10 \mathrm{~mm}$, taking some effective and reasonable measures is essential to prevent causing the asymmetrical shape or area near the blood vessel. Therefore, according to the location of tumor and blood vessel, the temperature contour of numerical simulation by different conditions could provide numerical references, which is whether to block the blood vessel or not, to achieve the aim of guiding the clinical practice. 


\section{Acknowledgments}

This research is supported by National Science Foundation of China (No. 31070754), Beijing Municipal Commission of Education Project Scientific and Technological Program (KM201410005028), the Importation and Development of High-Caliber Talents Project of Beijing Municipal Institutions for three years (2013-2015)-Nan Qun, and Basic Research Foundation of Beijing University of Technology (X4015999201401).

\section{References}

[1] T. Seki, M. Wakabayashi, T. Nakagawa, T. Itho, T. Shiro, K. Kunieda, M. Sato, S. Uchiyama and K. Inoue, Ultrasonically guided percutaneous microwave coagulation therapy for small hepatocellular carcinoma, Cancer 74.3 (1994), 817-825.

[2] G. Godlewsdi, S. Rowy, C. Pigmodei, H. Ould-Said, J.J. Eledjam, J.M. Bourgeois and P. Sambuc, Deep localized Neodymium (ND)-YAG laser photocoagulation on liver using a new water cooled and echoguided handpiece, Lasers in Surgery and Medicine 8.5 (1988), 501-509.

[3] Y.Y. Sun, Ablation in hepatic tissue and risk factors of hepatocellular carcinoma recurrence after microwave ablation, Chinese PLA General Hospital Medical School of Chinese P1A, 2007, pp. 20-24.

[4] Q. Nan, Y. Lu, R. Liu and Y. Zeng, Large blood vessel effect on thermal ablation with a water-cooled microwave antenna, Biomedical Engineering and Informatics (BMEI) 3 (2010), 936-938.

[5] Rattanadecho Phadungsak and P. Keangin, Numerical study of heat transfer and blood flow in two-layered porous liver tissue during microwave ablation process using single and double slot antenna, International Journal of Heat and Mass Transfer $\mathbf{5 8 . 1}$ (2013), 457-470.

[6] N. Snoeren, M.W. Nijkamp, T. Berendsen, K.M. Govaert, C.S. van Kessel, I.H.B. Rinkes and van R. Hillegersberg, Multipolar radiofrequency ablation for colorectal liver metastases close to major hepatic vessels, The Surgeon 13 (2015), 77-82.

[7] H.H. Pennes, Analysis of tissue and arterial blood temperatures in the resting human forearm, Journal of Applied Physiology 1 (1948), 93-122.

[8] A.S. Gladman, S.R.H. Davidson, A.C. Easty, M.L. Joy and M.D. Sherar, Infrared, thermographic SAR measurements of interstitial hyperthermia applicators: Errors due to thermal conduction and convection, International Journal of Hyperthermia 20.5 (2004), 539-555.

[9] Y. Liu, X. Yang, Q. Nan, J. Xiao, M.Y. Sun, W. Hua and D.S. Mao, Phantom experimental study on microwave ablation with a water-cooled antenna, Hyperthermia 23.4 (2007), 381-386.

[10] Y.L. Lu, Q. Nan and L. Li, Numerical study on thermal field of microwave ablation with water-cooled antenna, Hyperthermia 25.2 (2009), 108-115.

[11] Y.L. Lu, Q. Nan, J.J. Du, A.K. Qiao and Y.J. Liu, Experimental study on thermal field in the vicinity of arterial bifurcation in microwave ablation therapy, Hyperthermia 26.4 (2010), 316-326. 